\section{Multivariate regression analysis of prime variables affecting ophthalmic patients' satisfaction in a resource limited economy}

\author{
Emmanuel Olu Megbelayin, ${ }^{1}$ \\ Jacob Sackey ${ }^{2}$ \\ 'Department of Ophthalmology, \\ University of Uyo Teaching Hospital, Uyo; \\ ${ }^{2}$ ALACHE Microfinance Bank Limited, \\ Ogoja, Nigeria
}

\section{Abstract}

The aim of the present study was to appraise prime dependent variables of ophthalmic patients' satisfaction in a Nigerian public eye care facility with a view to boosting service uptake. It was a cross sectional study conducted between March and May 2012 in our centre. Consecutive clinic patients $(n=251)$ that met study's criteria were recruited. The patients filled interviewer-administered structured questionnaires. A total of 251 patients were analyzed comprising 139 males (55.4\%) and 112 females (44.6\%). Male:female ratio=1:0.8 The ages of the patients studied ranged from 17 to 92 years with a mean of 37.2 years \pm 15.57 . Bivariate analysis, validated by multiple logistic regression, showed $P$ values of $0.021,0.008$, 0.036, 0.008 and 0.004 for privacy, comfort during eye exam, fairness (non-partiality), thoroughness of examination and expectation, respectively. Satisfaction with overall quality of services was $80.1 \%$. The services of any eye facility should be patient-driven to attain desired goals; therefore the identified areas of patients' dissatisfaction should be addressed for effective service uptake.

\section{Introduction}

One of the factors that influence patient satisfaction is efficiency of services. Efficiency has a broad scope that embraces promptness of care, duration of consultation, quick response to emergencies, quick dispensation of drugs, fast and accurate laboratory tests, privacy, comfort during exam, fairness (non-partiality), thoroughness of examination and expectation. ${ }^{1}$ The extent to which the patients perceive these needs and expectations are met by the service provider determines satisfaction. ${ }^{2}$ With dwindling government earnings and health care becoming increasingly privatized and economically competitive, evidenced by privatization and commercialization of some of
Nigeria's public institutions, there is urgent need for patient-centered health services. Other reasons that have necessitated a shift towards business approach to healthcare delivery are intense competition, more patient awareness, increased purchasing power of patients, and availability of specialist care.,34

Public health systems in developing countries have failed to achieve adequate level of services. Nigeria, for instance, satisfaction to public health care is considerably low. ${ }^{2}$ To improve public participation and effectiveness of health programs, one must understand the underlying factors that contribute to patients' satisfaction. The success of any public institution should be consumer-driven to attain desired goals. Interest has grown not only in the assessment of treatment interventions by patients, but in the systematic evaluation of the delivery of that care.

This study attempted to define the level of ophthalmic health-care satisfaction in a cohort of Nigerian patients, as well as to further explore its primary determinants.

\section{Materials and Methods}

\section{Setting}

Our centre is a public tertiary referral centre in the heart of a state capital. The Ophthalmology department is one of the oldest clinical units in the hospital that could be a window to the services rendered in this public institution. The hospital statutory activities include research, training of various cadres of health professional and clinical services to the state of location and not exclusively, 5 other neighbouring states in Nigeria

\section{Design of the study and sampling technique}

This was a cross sectional study. A total sampling of all consecutive patients who met the inclusion criteria and who presented within the study time frame were studied.

\section{Population}

This study was conducted among adult patients attending Eye Clinic in our centre between March and May 2012.

\section{Sample size}

To determine the sample size of this study, the following formula was used:

$\mathrm{N}=\frac{\mathrm{Z}^{2} \mathrm{pq}}{\mathrm{d}^{2}}$

where $\mathrm{N}$ represents minimum sample size required, $\mathrm{P}$ stands for prevalence (from previ-
Correspondence: Emmanuel Olu Megbelayin, Department of Ophthalmology, University of Uyo Teaching Hospital, Abak road, Uyo, Nigeria.

Tel/Fax: +234.8036.670920.

E-mail: favouredolu@yahoo.com

Key words: multiple logistic regressions, satisfaction, patients, Calabar, Nigeria.

Acknowledgements: we would like to thank the medical students who assisted in data collection and the entire Eye Clinic staff for their overall support throughout the study.

Contributions: EOM: concept and design, definition of intellectual content, literature search, acquisition of data, data analysis and interpretation, drafting of the article and final approval of the version to be published; JS: concept and design, definition of intellectual content, literature search and final approval of the version to be published.

Conflict of interests: the authors declare no potential conflict of interests.

Received for publication: 19 February 2013

Revision received: 21 June 2013.

Accepted for publication: 14 July 2013.

This work is licensed under a Creative Commons Attribution 3.0 License (by-nc 3.0).

(C) Copyright E.O. Megbelayin and J. Sackey, 2014 Licensee PAGEPress, Italy

Healthcare in Low-resource Settings 2014; 2:1390 doi:10.4081/hls.2014.1390

ous study) $=83 \%, \mathrm{q}=1-\mathrm{P} / 100$, i.e. $1-83 / 100=1-$ $0.83=0.17 . \mathrm{Z}$ is standard normal deviation of 1.96 (which corresponds to $95 \%$ confidence interval), while $Z^{2}=3.84$. Degree of accuracy desired (d) was $0.05\left(d^{2}=0.0025\right)$.

Substituting the above figures in the formula, we obtained:

$\mathrm{N}=\frac{\mathrm{Z}^{2} \mathrm{pq}}{\mathrm{d}^{2}}=\frac{3.84 \times 0.83 \times 0.17}{0.0025}=217$

Thus the sample size calculated using the above formula was 217. In order to make an allowance for non-responders, an attrition rate of $10 \%$ of the calculated sample size was added to the 217 sample size to obtain a figure of 239 .

\section{Inclusion and exclusion criteria}

The inclusion criteria used in this study were as follows: i) age more than 16 years; ii) patients who were duly registered in the Eye Clinic and seen by a doctor at least once.

Conversely, the exclusion criteria were: i) age 16 years and below (UNICEF definition of a child is 16 years and below; ${ }^{5}$ children were deliberated excluded in this response-based 
study to enhance reliability). Adults' appreciation of service provided is more likely to be objective; ii) non-eye patients of the hospital; iii) eye patients not yet seen by a doctor, whether registered or not.

\section{Pilot study}

Questionnaire was validated through pretest study that lasted one week conducted at the Eye Clinic of a peripheral health facility attached to our centre. This was to test research tools and to train data collectors in order to minimize inter and intra-observer variations.

\section{Consents and ethical approval}

Ethical approval was obtained from the Ethics Committee of our centre. Written and oral informed consents were sought from every participant in accordance with the tenets of Helsinki declaration.

\section{Data collection proper}

The study was based on primary information collected through pretested questionnaire from consecutive patients of the Eye Clinic. Only clinic patients were involved in the study to maintain homogeneity. Structured questionnaires grossly divided into two parts was specifically developed for this study. The first part was on biodata to get basic information from patients including occupation and educational levels. The second part was a two-section, 10-items questionnaire to cover areas of research interest. All ratings were made on a modified 6-point Likert-type scales.

Among others, questions contained in the questionnaire included socio-demographics characteristics, patient-provider relationship, issues on expectation, hospital appearance and adequacy of facilities in the eye clinic. Questionnaires were filled by literate patients while medical students, specifically trained in the conduct of interviews assisted illiterate patients. Communication among respondents was discouraged to check undue interferences.

The items in the questionnaires were adapted from existing instruments used in previous patient satisfaction survey. ${ }^{6}$ Options provided for patients to choose from included undecided or non-applicable to ensure patients were not forced to tick options which might not be relevant to them.

Patient indicated their level of satisfaction by the following options: agree, strongly agree, disagree and strongly disagree. Those who chose disagree and strongly disagree were considered dissatisfied while those who selected agree and strongly agree were considered satisfied. Focus Group Discussions (FGDs) were held among the participants in batches during each clinic session. During the FGDs, filled questionnaires with vague entries were clarified to douse ambiguity. One of the authors supervised data collection.

\section{Data analysis}

The data from questionnaires were coded, entered and analyzed using SPSS (Statistical Package for Social Sciences) version 12 software in form of frequencies and percentages. Multivariate regression analysis was used to control for confounders, with categorical vari- ables compared by chi-square test. $\mathrm{P}$ values $<5 \%$ (0.05) were considered statistically significant.

\section{Results}

Of the 267 filled questionnaires, only 251 were found suitable for research work, comprising 139 males (55.4\%) and 112 females (44.6\%). Male:female ratio=1:0.8. The ages of the patients studied ranged from 17 to 92 years with a mean of 37.2 years \pm 15.57 . Table 1 shows age and sex distribution of the patients studied. 17 to 40 years constituted the highest age group. The adoption of this age grouping was on the premise that they share similar ideologies and not on any statistical prejudice.

Table 2 shows the responses of the subjects. About $30 \%$ of patients were dissatisfied for not being attended to in the order they arrived at the clinic. Majority of patients had pre-visit expectations meant in addition to being satisfied with patient-provider relationships, hospital appearance, manner of eye examination and level of privacy. The computed overall patient satisfaction with all services was $80.1 \%$. P values were $0.021,0.008,0.036,0.008$

Table 1. Age and sex distribution of the patients studied.

\begin{tabular}{lcccccc} 
Age (years) & & Male & \multicolumn{3}{c}{ Female } & \multicolumn{2}{c}{ Total } & n. \\
& n. & $\%$ & n. & $\%$ & 159 & 63.3 \\
$17-4$ & 79 & 31.5 & 80 & 31.9 & 70 & 27.9 \\
$41-60$ & 47 & 18.7 & 23 & 9.2 & 22 & 8.8 \\
\hline$>60$ & 13 & 5.2 & 9 & 3.6 & \\
\hline
\end{tabular}

Chi-squared $=6.127 ; \mathrm{P}=0.047$; degree of freedom $=2 ; 95 \%$ confidence interval $=0.045-0.069$.

Table 2. Responses of subjects.

\begin{tabular}{llccccc} 
& Question & S (\%) & NS (\%) & U (\%) & NA (\%) (\%) \\
1 & Confidentiality (privacy) & $175(69.7)$ & $38(15.1)$ & $15(6)$ & $8(3.2)$ & $15(6)$ \\
2 & Comfort of examinations & $199(79.3)$ & $31(12.4)$ & $11(4.4)$ & $2(0.8)$ & $8(3.2)$ \\
\hline 3 & Fairness (first come first serve was obeyed) & $141(56.2)$ & $74(29.5)$ & $22(8.8)$ & $6(2.4)$ & $8(3.2)$ \\
4 & Thoroughness of examination & $204(81.3)$ & $8(3.2)$ & $23(9.2)$ & $5(2)$ & $11(4.4)$ \\
\hline 5 & My expectation was meant & $188(74.9)$ & $11(4.4)$ & $37(14.7)$ & $6(2.4)$ & $9(3.6)$ \\
6 & Pharmacists were courteous & $157(62.5)$ & $24(9.6)$ & $28(11.2)$ & $38(15.1)$ & $4(1.6)$ \\
\hline 7 & Lab scientists were courteous & $122(48.6)$ & $18(7.2)$ & $46(18.3)$ & $60(23.9)$ & $5(2)$ \\
8 & Other hospital staff were courteous & $184(73.3)$ & $10(4)$ & $34(13.5)$ & $18(7.2)$ & $5(2)$ \\
\hline 9 & Nurses were caring & $203(80.9)$ & $24(9.6)$ & $16(6.4)$ & $2(0.8)$ & $6(2.4)$ \\
10 & Doctor was willing to explain your eye condition & $222(88.4)$ & $2(0.8)$ & $9(3.6)$ & $5(2)$ & $13(5.2)$ \\
\hline 11 & Doctor was caring & $225(89.6)$ & $6(2.4)$ & $12(4.8)$ & $4(1.6)$ & $4(1.6)$ \\
\hline
\end{tabular}

S, satisfied; NS, not satisfied; U, undecided; NA, not applicable; NR, no response. Source: compiled from questionnaires. 
and 0.004 for patients' privacy, comfort during eye exam, fairness (non-partiality) to patients, thoroughness of examination and patients expectation respectively. These key variables remained statistically significant after accounting for confounding factors such as literacy level, travels and socio-economic status. This is detailed in bivariate analysis in Table 3 and validated by multiple logistic regressions in Table 4.

\section{Discussion}

The interpretation of this study must be understood against the backdrop of the pervasive limitations inherent in this kind of study. The spectrum of patients being questioned varied and so could have been their responses. A homogenous population could have obviated biases introduced by confounders such as literacy level, travels and socio-economic status. Hospital-based studies have inherent selection biases to which this study could not be said to be immuned. The perception of satisfaction cannot be measured quantitatively while the qualitative alternative, being replete with subjectivity, is difficult to interpret.

The age distribution of the patients showed that majority, 159 (63.3\%) were between the ages of 17 and 40 years in conformity to a study in a similar institution in Kano. ${ }^{2}$ The mean age of 37.2 years was comparable with the 38 years reported by Umar et al. in Sokoto, Northern Nigeria but significantly lower than 45 years obtained in Karachi. ${ }^{7,8}$ There were more males than females in this study like another south- ern Nigerian study on patients' satisfaction. ${ }^{4}$ The finding of predominantly youthful male population taking advantage of public health facility might be because they are the working class and more likely to afford incurred expenses than their female counterparts who often depend on them, being from lower socioeconomic status in developing countries.

There have been inconsistencies in the figures obtained from patient satisfaction surveys across Nigeria in the order of $84,83,75$ and $53 \% .{ }^{2,9-11}$ Though the overall satisfaction of $80.1 \%$ of this study falls comfortably within this range, the reasons for varied figures are multifactorial. These would include individual study's methodology, setting and the target patients (population). Others are patients' expectation, socio-cultural differences and chequered political history and subsequent effects on public institutions in developing nations. The above studies cut across multiethno religious Nigeria with variegated opinions and inequality in the distribution, most times stark inaccessibility to basic amenities. The diverse satisfaction figures reported are thus not unexpected.

Among the dependent variables considered in this study, patients' privacy, comfort with examination, perception of equality of treatment, thoroughness of examination and patients' pre-visit expectations were specifically isolated for discussion. This was because they remained statistically significant after accounting for such confounding variables as literacy and socio-economic factors. Again, these variables are often not subjects of focus in many patients' satisfaction surveys. Reports of Woodside et al. showed that overall satisfac-

Table 3. Bivariate analysis showing correlation between overall satisfaction and specific variables.

\begin{tabular}{lccccc} 
Variables & P value & $\begin{array}{c}\text { Pearson } \\
\text { chi-square }\end{array}$ & Odds ratio & $95 \%$ CI & df \\
Privacy & 19.502 & 0.021 & 11.630 & $0.019-0.084$ & 9 \\
Comfort during examination & 62.477 & 0.008 & 11.048 & $0.000-0.019$ & 9 \\
\hline Partiality & 26.150 & 0.036 & 10.361 & $0.013-0.059$ & 9 \\
Thoroughness of check-up & 34.610 & 0.008 & 15.729 & $0.000-0.019$ & 9 \\
\hline Expectation & 42.061 & 0.004 & 22.278 & $0.000-0.012$ & 9 \\
\hline
\end{tabular}

$\mathrm{Cl}$, confidence interval; df, degree of freedom. Source: compiled from questionnaires.

Table 4. Multivariate logistic regressions for overall satisfaction with quality of eye care.

\begin{tabular}{lcc}
\hline Variables & $95 \%$ CI & P \\
Privacy (confidentiality intact) & $0.650-1.656$ & $<0.001$ \\
Comfort during eye examination & $0.939-1.738$ & $<0.001$ \\
\hline Fairness (no partiality) & $1.139-2.187$ & $<0.001$ \\
Thoroughness of examination & $0.361-1.342$ & 0.001 \\
\hline Expectation was meant & $0.564-1.659$ & $<0.001$ \\
\hline
\end{tabular}

CI, confidence interval.

\section{Conclusions}

Based on the findings, this article concludes that to enhance satisfaction, it is important to give patient-centered care. This is health care that is responsive to patients' wants, needs, and preferences. This is against the backdrop 
that the choice and eventual success of many treatment options are based on subjective patient-defined criteria. It is recommended that exit suggestion boxes should be strategically located at patients' departure points to solicit suggestions on how services could be improved upon. Providing grievances redressal system for aggrieved patients to access is a pragmatic step of showing genuine concern for improving patient satisfaction. Periodic patient satisfaction survey should be institutionalized to provide feedback for continuous quality improvement. And most importantly, excellent health care can only be achieved when all the cadres of staff work as a team and as stakeholders. There should be routine stakeholders training workshops where health care workers are trained and re-trained on ways of improving quality of services.

\section{References}

1. Santillan D. Uses of satisfaction data: report on improving patient care. Soc Sci Med 2000;12:24-6.

2. Iliyasu Z, Abubakar IS, Abubakar S, et al. Patients' satisfaction with services obtained from Aminu Kano Teaching Hospital, Kano, Northern Nigeria. Niger J Clin Pract 2010;13:371-8.

3. Yadav K. Health services: the Indian scene marketing of services-concept and applications. In: Khurana R, Kaushik M and Yadav K, eds. New Delhi: Indira Gandhi National
Open University; 1993. pp 141-9.

4. Olawoye 00. Patient satisfaction with cataract surgery and posterior chamber intraocular lens at University College Hospital Ibadan and St Mary's Catholic Hospital Ago-Iwoye, Nigeria. Ijanikin: National Postgraduate Medical College of Nigeria; 2008. pp 9-10.

5. WHO. Report of a WHO/APB scientific meeting. Preventing blindness in children. WHO/PBL/77. Geneva: World Health Organization; 1999.

6. Ware JE, Snyder MR, Wright R. Defining and measuring patient satisfaction with medical care. Eval Program Plann 1993;6: 247-63.

7. Umar I, Oche MO, Umar AS. Patient waiting time in a tertiary health institution in Northern Nigeria. J Public Health Epidemiol 2011;3:78-82.

8. Jawaid M, Ahmed N, Alam SN, et al. Patients' experiences and satisfaction from a surgical outpatient department of a tertiary care teaching hospital. Pak J Med Sci 2009;25:439-42.

9. Ofili AN, Ofovwe CE. Patients' assessment of efficiency services at a teaching hospital in a developing country. Ann Afr Med 2005;4:150-3.

10. Olusina AK, Ohaeri JU, Olatawura MO. Patient and staff satisfaction with the quality of in-patient psychiatric care in a Nigerian general hospital. Soc Psych Psych Epid 2004;37:283-88.

11. Eze CU. Survey of patient satisfaction with obstetric ultrasound at University of
Nigeria Teaching Hospital Enugu, Nigeria. Niger J Health Biomed Sci 2006;5:93-7.

12. Woodside AG, Frey LL, Daly RT. Linking service quality, patient satisfaction and behavioural intention. J Health Care Mark 1989;7:61-8.

13. Anderson D. The satisfied patient: service return behaviour in the hospital obstetrics market. J Health Care Mark 1992;2:25-33.

14. Ogunfowokan 0, Mora M. Time, expectation and satisfaction: patients' experience at National Hospital Abuja, Nigeria. Afr J Prim Health Care Fam Med 2012;4:1-6.

15. Sharma RD, Hardeep C. A study of patient satisfaction in outdoor services of private health care facilities. Accessed on 18/02/2013. Available from: www.vikalpa. com/pdf/articles/1999/1999_oct_dec_079_ 076.pdf

16. Oreniga 00, Sofola 00, Uti 00. Patient satisfaction: a survey of dental outpatients at the Lagos University Teaching Hospital, Nigeria. Nig Q J Hosp Med 2009;19:47-52.

17. Ajayi IO, Olumide EA, Oyediran 0. Patient satisfaction with the services provided at a general outpatients' clinic, Ibadan, Oyo state, Nigeria. Afr J Med Med Sci 2005;34: $33-40$.

18. Net N, Chompikul J, Sermsri S. Patient satisfaction with health services in the out-patient department clinic of nangmamyen community hospital Sakeao province, Thailand. J Public Health Dev 2007;5:33-42. 